\title{
Comparison of predicted aquatic risks of pesticides used under different rice-farming strategies in the Mekong Delta, Vietnam
}

\author{
Nadja Stadlinger ${ }^{1,2}$ - Håkan Berg ${ }^{2}$ Paul J. Van den Brink ${ }^{3,4}$ - Nguyen. T. Tam ${ }^{2,5}$. \\ Jonas S. Gunnarsson ${ }^{1}$
}

Received: 26 February 2016 / Accepted: 25 October 2016 / Published online: 16 November 2016

(C) The Author(s) 2016. This article is published with open access at Springerlink.com

\begin{abstract}
This study evaluates the risks of pesticides applied in rice-fish and rice farming, with and without integrated pest management (IPM) strategies, to non-target aquatic organisms in two provinces of the Mekong Delta, Vietnam. Pesticide inventories and application patterns were collected from 120 Vietnamese farmers through interviews. Risks were assessed using (1) Pesticide RIsks in the Tropics to Man, Environment, and Trade (PRIMET), a first-tier model, which calculates predicted environmental concentrations (PECs) of pesticides in the rice field, based on the compound's physico-chemical properties and the application pattern, and then compares the PECs to safe concentrations based on literature data, and (2) species sensitivity distribution (SSD), a second-tier assessment model using species sensitivity distributions to calculate potentially affected fraction (PAF) of species based on the PECs from PRIMET. Our results show that several of the used insecticides pose a high risk to fish and arthropods and that the
\end{abstract}

Responsible editor: Philippe Garrigues

Nadja Stadlinger

nadja.stadlinger@natgeo.su.se

$\triangle$ Jonas S. Gunnarsson

jonas.gunnarsson@su.se

1 Department of Ecology, Environment and Plant Sciences, Stockholm University, Stockholm, Sweden

2 Department of Physical Geography, Stockholm University, Stockholm, Sweden

3 Department of Aquatic Ecology and Water Quality Management, Wageningen University, Wageningen, the Netherlands

4 Alterra, Wageningen University and Research Centre, Wageningen, the Netherlands

5 Department of Aquaculture, Nong Lam University, HCM City, Vietnam risks are higher among rice farmers than among rice-fish farmers. This study indicates that the PRIMET model in combination with SSDs offer suitable approaches to help farmers and plant protection staff to identify pesticides that may cause high risk to the environment and therefore should be substituted with safer alternatives.

Keywords Risk assessment - Plant protection products . Rice $\cdot$ Pesticide management $\cdot$ Fish $\cdot$ Integrated pest management $\cdot$ PRIMET $\cdot$ Species sensitivity distribution

\section{Introduction}

Vietnam is currently ranked as the fifth largest rice producer in the world, with most of its rice being farmed in the Mekong River Delta (Ricepedia 2016). The use of pesticides has helped to increase rice yields but has also led to an increased pollution that presents a potential toxicity threat to the environment and public health (Carvalho et al. 2008; Berg and Tam 2012; Tam et al. 2015a, b). A recent study found high concentrations of pesticides in sediment and drinking water of the Mekong Delta, indicating that pesticides may pose a chronic exposure risk to biota and humans (Toan et al. 2013). Several programs have been launched since 1992 in Vietnam in order to train rice farmers to reduce their pesticide use, such as integrated pest management (IPM) programs (Fig. 1). In 2005, about one million farmers had received training through Farmer Field Schools corresponding to more than $10 \%$ of all rice-farming households in the country (Van de Fliert et al. 2007). Several information campaigns on safer pesticide use have also been launched in order to help famers reduce their pesticide use in the delta (Huan et al. 1999, 2008). Some farmers practice integrated rice-fish culture in the delta that can provide a sustainable alternative to rice monocultures, 
Fig. 1 Examples of pesticide application, disposal, and IPM training in the Mekong Delta. Farmer spraying his rice field $(l e f t)$, disposed pesticide containers in a ditch (middle), and farmers involved in IPM training $($ right $)$

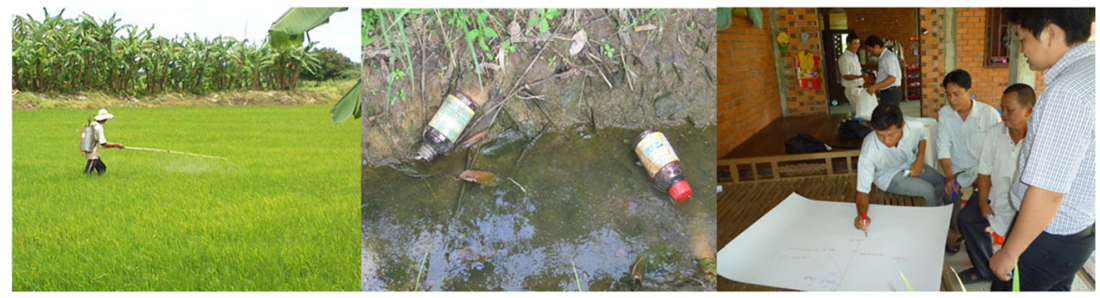

as these farmers tend to decrease their use of pesticides for an optimized production of both rice and fish (Berg 2002; Berg and Tam 2012). This can also help to spread the farmers' economic risks since the fish provides an extra important source of income. It is considered as a low external input system ( $\mathrm{Lu}$ and $\mathrm{Li}$ 2006) that enhances ecosystem services for the benefit of local people's livelihood and well-being (Berg et al. 2012). Integrated rice-fish farming is, however, vulnerable to the negative side effects of pesticides as fish are stocked directly in the rice fields. Earlier studies indicate that a high use of pesticides may impact fish growth and survival (Berg 2002; Tam et al. 2015a; Tam et al. 2016b). This could be through direct toxic effects on the fish but also through indirect impacts on different ecosystem services provided by the rice-field environment that helps to sustain a high production of both rice and fish. IPM is therefore seen as an important complementary strategy to make rice-fish farming an economic competitive alternative to rice monocultures (Berg 2002).

The Vietnamese Mekong Delta covers an area of $40,000 \mathrm{~km}^{2}$ and is the most important agricultural region of Vietnam (Fig. 2). Covering only $12 \%$ of Vietnam's total land area, it supplies more than half of the national rice output and provides $90 \%$ of Vietnam's rice exports (General Statistics Office 2009; Johnston et al. 2010). Rice yields are the highest of the country in this region, with up to 15 metric tons per hectare and year (Cao 2011). The average farm size is between 1.0 and 1.8 ha (Sanh et al. 1998; Bosma et al. 2009; Berg and Tam 2012). Chemical fertilizers are more commonly applied by the farmers than organic fertilizers. Pesticides are commonly used with an average dose between 1 and $1.5 \mathrm{~kg}$ of active ingredient per hectare and crop (Duong et al. 2005; Berg and Tam 2012).

Large areas of the Mekong Delta are suitable for freshwater aquaculture, but historically, only minor areas have been used for this purpose (Nhan et al. 2007). Recently, however, aquaculture has been expanding rapidly (Nhan et al. 2007; General Statistics Office 2007; Phan et al. 2009), especially catfish farming (De Silva and Phuong 2011). The delta accounts for $70 \%$ of Vietnam's aquaculture production (Johnston et al. 2010), which calls for a more restrictive use of pesticides and other agro-chemicals to assure an acceptable water quality for a sustainable and healthy fish production (cf. Nhan et al. 2007; Andrieu et al. 2015). The climate in the delta is characterized as tropical semi-equatorial with an annual average

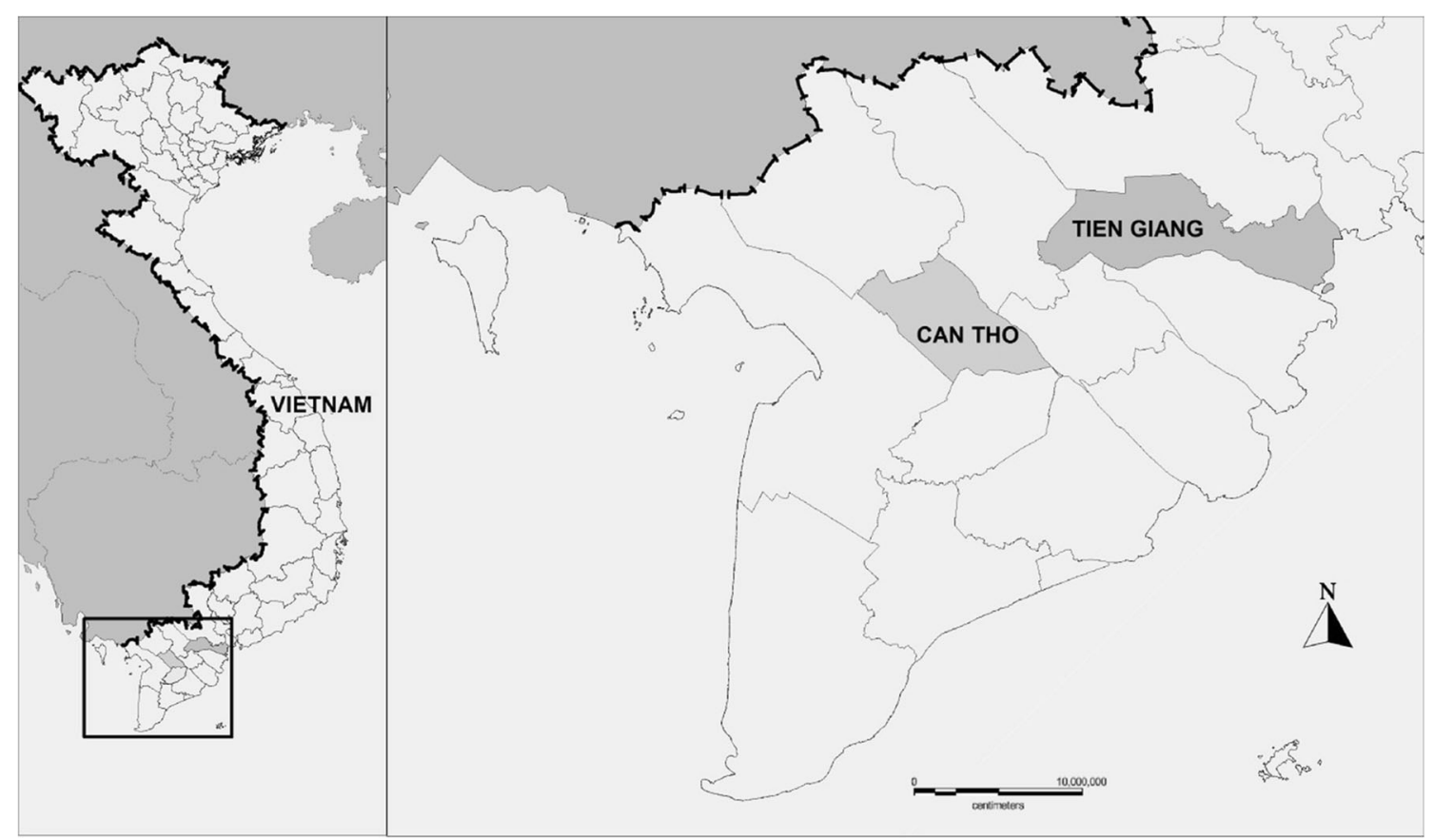

Fig. 2 Map showing the location of the provinces Can Tho and Tien Giang in the Mekong Delta of Vietnam 
temperature of $27^{\circ} \mathrm{C}$. The mean annual rainfall is $1600 \mathrm{~mm}$, and approximately $90 \%$ of the rain come during the rainy season in May to October (General Statistics Office 2009).

This study aims to evaluate if the use of pesticides among rice farmers and rice-fish farmers in the Mekong Delta poses a risk for direct toxicological effects on aquatic organisms living in the rice fields, with a focus on fish. The study also aims to evaluate if this risk differs between different farming strategies such as rice monoculturing, IPM, and integrated rice-fish farming. The risk is estimated using the screening model tool Pesticide RIsks in the Tropics to Man, Environment and Trade (PRIMET) (Peeters et al. 2008), which is a decision support system for assessing pesticide risks in the tropics. PRIMET is a freely available program, which needs a minimum of pesticide input data. It is designed to be used in tropical countries, taking into account temperature-dependent pesticide parameters. PRIMET can evaluate pesticide risks to aquatic life, earthworms, bees, non-target arthropods, drinking water, and dietary exposure (Peeters et al. 2008). To our knowledge, PRIMET has never been used to assess the risks of pesticide use under different rice-farming scenarios in the tropics before. Risks were further investigated using the species sensitivity distribution (SSD) model (Posthuma et al. 2002), in order to more specifically assess the risks for fish. The current trend in the delta is towards an intensified production of both fish and rice, and this is a first attempt to estimate if the current use of pesticides may pose risks to fish and other non-target aquatic organisms and, thus, be a problem for a sustainable production of both rice and fish in the Mekong River Delta.

\section{Material and methods}

Pesticide use among rice farmers in the Can Tho City and Tien Giang Provinces of the Mekong Delta in southern Vietnam was assessed through questionnaires and interviews (Berg and Tam 2012). The study involved 120 farmers divided into conventional rice farmers (R), conventional rice-fish farmers (RF), rice farmers with training in integrated pest management (RIPM), and rice-fish farmers with training in integrated pest management (RFIPM). Each interview group in each province consisted of approximately 15 farmers. IPM farmers were defined as farmers, who had attended some form of training in IPM. Interviews were made with farmers, who had two or three rice crops per year, as these are the systems with the highest use of pesticides (Berg and Tam 2012). In this paper, we conducted a risk assessment of the pesticides identified in Berg and Tam (2012) to non-target aquatic organisms, i.e., fish and aquatic arthropods living in the rice-fish-farming system and compare the predicted risks among the four farming systems $(\mathrm{R}, \mathrm{RF}$, RIPM, RFIPM).

\section{Study area}

The Tien Giang Province and Can Tho City (same administrative level as a province) were selected as study sites because they are two typical areas for rice and rice-fish farming in the Mekong Delta (Berg 2002; Nga and Sinh 2008). The districts of Go Cong Tay $\left(272 \mathrm{~km}^{2}\right)$ and Cai Be $\left(421 \mathrm{~km}^{2}\right)$ represent two different rice-producing areas within the Tien Giang Province. The dominant farming systems in the Cai Be District are rice and fruit cultivation, while rice and vegetable cultivation are dominant systems in the Go Cong Tay District. The areas around Cai Be are well irrigated through a network of many canals and natural rivers. The first rice crop is usually grown from November to February (the winter-spring crop), the second from February to May (the summer-autumn), and the third from May to August (the autumn-winter crop). Go Cong Tay has a much poorer irrigation system compared to the Cai Be Province. The first rice crop is grown from November to January, the second from May to August, and the third from September to November. The O Mon $\left(126 \mathrm{~km}^{2}\right)$ and Co Do $\left(403 \mathrm{~km}^{2}\right)$ Districts, which lie in Can Tho City, are also representative of the irrigated rice areas of the Mekong Delta, both in aspects of physical environment and productivity. Rice is cultivated in the dry and wet seasons using the double rice-cropping system and in the dry, spring-summer, and wet seasons using a triple rice system. Fish is usually farmed either together with the rice or in the flooded season, when the rice has been harvested. There is usually only one fish harvest per year. The most commonly farmed species are silver carp, common carp, silver barb, climbing perch, snakeskin gourami, and Nile tilapia (Berg 2002; Cao 2011).

\section{Pesticide application input data}

The interview data from Berg and Tam (2012) was compiled into recorded active ingredients and amounts of applied active ingredients per hectare and crop. Pesticide products with more than one active ingredient were separated into active ingredients and percentage based on producers' information. All application data was divided into single-application scenarios of an active ingredient per rice field and season (up to three crops per year). If one active ingredient was repeatedly used on one rice field and crop, it was included as a repeated application $(n>1)$, and the time interval between applications $(\Delta t)$ was included (Table 1). In case the time interval between applications was missing in the interview data, a calculated average of days between applications for insecticides, herbicides, and fungicides, respectively, was used. The data was coded so that farmer ID, management regime, rice field, and crop were traceable for each application scenario. The input data sheet resulted in approximately 700 individual application scenarios (Table 3). 
Table 1 Pesticide application input parameters in PRIMET, where $M, n$, and $\Delta t$ vary with each application scenario

\begin{tabular}{lll}
\hline Parameter & In PRIMET & Source \\
\hline Individual dose applied (g A.I./ha) & $M$ & Interview data \\
Percentage spray drift (\%) & Drift & Worst-case estimation \\
Percentage spray drift to ditch (\%) & Drift-ditch & Worst-case estimation \\
Number of applications (-) & $n$ & Interview data \\
Time interval between applications (day) & $\Delta t$ & Interview data \\
\hline
\end{tabular}

\section{PRIMET}

The data on pesticides' use among farmers was used as input data for the PRIMET model, which is "a decision support system for assessing Pesticide RIsks in the Tropics to Man, Environment, and Trade" (Peeters et al. 2008). The model calculates an exposure toxicity ratio $(\mathrm{ETR}=$ predicted environmental concentration (PEC)/predicted no effect concentration (PNEC)) for different scenarios of pesticide applications on a model water body with physical parameters that can be predefined. ETR values are classified as $<1=$ "no risk," $1-$ $100=$ "possible risk," and $>100=$ "definite risk" based on worst-case assumptions. Both acute and chronic risk quotients are obtained from PRIMET. The acute ETR value (ETR $n_{\text {water- }}$ acute) is obtained from concentrations based on $n$ applications $(\mathrm{PEC} n$ water $)$ and acute $\mathrm{EC}_{50}$ values for fish, crustaceans (Daphnia), and algae (PNEC water-acute). The chronic ETR value (ETR water-chronic) is derived from the lowest coefficient of either the average water concentration for fish (28 days) or Daphnia (21 days), divided by the respective chronic no effect concentration (Peeters et al. 2008). The physical input parameters were determined based on in situ measurements and literature estimates from the Mekong Delta area (Table 2). The pesticide application doses were derived from the interviews with farmers from the four pesticide management types (R, RF, RIPM, RFIPM) (Table 3). Spray drift to ditch (Table 2) was set to $100 \%$, as the PRIMET model does not include runoff and thereby underestimates the amount of pesticide that reaches the water (Peeters et al. 2008). Also, rice fields are wetlands in direct contact with water, which increases the exposure of aquatic organism to pesticides sprayed on rice compared to other crops such as vegetables and fruits. The PRIMET active ingredient (A.I.) database was completed and updated with information on pesticide characteristics from the footprint Pesticide Properties Database (Lewis et al. 2016). If the half-life for water/sediment was missing, a conservative estimate of 999 days was used. This parameter is needed for calculations of the risks to the aquatic life in PRIMET but is not always available for all substances. All scenarios were analyzed in PRIMET version 3.0. The calculated PECs from PRIMET were then also used to estimate the potentially affected fraction (PAF) using the SSDs for the pesticides of the highest concern.

\section{SSDs}

To further evaluate the risks for aquatic organisms within the rice fields, SSD curves were calculated for substances with estimated ETR acute values above 100 (Tables 3 and 4). Toxicity data for each substance was primarily collected from US EPA Ecotox Database (2016) and De Zwart (2002). In some cases, the PAN Pesticide Database (2014) was used to complement the other two databases. Identical records from multiple databases were removed, and no values given as ranges or "higher/lower than" were used. For two insecticides with plenty of fish toxicity data available, the data set was
Table 2 Physical scenario parameters of the water body/rice field as defined in PRIMET

\begin{tabular}{lll}
\hline Parameter & Value & Source \\
\hline Bottom width of the water body $(\mathrm{m})$ & 100 & Field estimation \\
Depth of water body $(\mathrm{m})$ & 0.34 & Field estimation \\
Length of water body $(\mathrm{m})$ & 100 & Field estimation \\
Mass fraction organic matter in suspended & $0.25^{\mathrm{a}}$ & Average organic content (\%) (low-exchange pond; \\
$\quad$ solids (g/g) & & Hoa et al. 2003) \\
Mass concentration of suspended solids in & $0.0001^{\mathrm{a}}$ & 100 mg/L (Sebesvari et al. 2012) \\
$\quad$ water $(\mathrm{kg} / \mathrm{L})$ & $301^{\mathrm{a}}$ & Average temperature (low-exchange pond; Hoa et al. \\
Ambient temperature in the scenario $(\mathrm{K})$ & & 2003) \\
Side slope & 0.33 & Field estimation \\
Flow velocity (m/day) & 0.001 & Field estimation \\
\hline
\end{tabular}

${ }^{\mathrm{a}}$ Data taken from literature source 
Table 3 All active ingredients identified from the interview study, their occurrence in each province and per management regime, number of users and single-application scenarios, and how they were further assessed

\begin{tabular}{|c|c|c|c|c|c|c|c|c|}
\hline Active ingredient & $\begin{array}{l}\text { Use } \\
\text { type }\end{array}$ & Chemical class ${ }^{\mathrm{b}}$ & $\begin{array}{l}\text { Occurrence } \\
\text { (province) }^{\mathrm{c}}\end{array}$ & $\begin{array}{l}\text { Occurrence } \\
\text { management } \\
\text { regimes }^{\mathrm{d}}\end{array}$ & $\begin{array}{l}\text { No. of } \\
\text { users }\end{array}$ & $\begin{array}{l}\text { No. of application } \\
\text { scenarios }\end{array}$ & $\begin{array}{l}\text { Assessed with } \\
\text { PRIMET }\end{array}$ & $\begin{array}{l}\text { Assessed } \\
\text { with SSD }\end{array}$ \\
\hline Alpha-cypermethrin & I & Pyrethroid & $\mathrm{CT}$ & R, RIPM, RF, RFIPM & 8 & 22 & $\mathrm{x}$ & $\mathrm{x}$ \\
\hline Bensulfuron-methyl & $\mathrm{H}$ & Sulfonylurea & TG & $\mathrm{RF}$ & 1 & 6 & - & - \\
\hline Buprofezin & I & Unclassified & CT, TG & R, RIPM, RF, RFIPM & 11 & 21 & $\mathrm{x}$ & - \\
\hline Butachlor & $\mathrm{H}$ & Chloroacetanilide & TG & R, RIPM, RF, RFIPM & 17 & 50 & $\mathrm{x}$ & - \\
\hline Cartap & I & Nereistoxin & CT, TG & R, RF, RFIPM & 10 & 30 & - & - \\
\hline Diazinon & I & Organophosphorus & $\mathrm{CT}$ & $\mathrm{R}, \mathrm{RF}$ & 2 & 4 & $\mathrm{x}$ & $\mathrm{x}$ \\
\hline Ethoxysulfuron & $\mathrm{H}$ & Sulfonylurea & TG & R, RIPM & 2 & 6 & $\mathrm{x}$ & - \\
\hline Etofenprox & I & Pyrethroid ether & $\mathrm{CT}$ & R, RIPM, RFIPM & 4 & 10 & $\mathrm{x}$ & $\mathrm{x}$ \\
\hline Fenclorim $^{\mathrm{f}}$ & $\mathrm{H}$ & Unclassified & CT, TG & R, RIPM, RF, RFIPM & 21 & 49 & $\mathrm{x}$ & - \\
\hline Fenobucarb & I & $\begin{array}{l}\mathrm{N} \text {-methyl } \\
\text { carbamate }\end{array}$ & CT, TG & R, RIPM, RF, RFIPM & 55 & 154 & $\mathrm{x}$ & $\mathrm{x}$ \\
\hline Fenoxaprop-P-ethyl & $\mathrm{H}$ & $\begin{array}{l}\text { Aryloxyphenoxy } \\
\text { propionic acid }\end{array}$ & CT, TG & R, RIPM, RF & 3 & 8 & $\mathrm{x}$ & - \\
\hline Fipronil & I & Pyrazole & $\mathrm{CT}$ & R, RIPM, RF, RFIPM & 7 & 17 & $\mathrm{x}$ & $\mathrm{x}$ \\
\hline Glyphosate & $\mathrm{H}$ & Phosphonoglycine & $\mathrm{CT}$ & RIPM & 1 & 1 & $\mathrm{x}$ & - \\
\hline Hexaconazole & $\mathrm{F}$ & Azole & CT, TG & R, RIPM, RF, RFIPM & 43 & 113 & $\mathrm{x}$ & - \\
\hline Imidacloprid & I & Neonicotinoid & CT, TG & R, RIPM & 3 & 12 & $\mathrm{x}$ & - \\
\hline Iprodione & $\mathrm{F}$ & Dicarboximide & $\mathrm{TG}$ & $\mathrm{R}, \mathrm{RF}$ & 2 & 6 & $\mathrm{x}$ & - \\
\hline Isoprocarb & I & $\begin{array}{l}\text { N-methyl } \\
\text { carbamate }\end{array}$ & $\mathrm{CT}$ & R, RIPM, RF & 3 & 6 & - & - \\
\hline Isoprothiolane & $\mathrm{F}$ & Unclassified & CT, TG & R, RIPM, RFIPM & 5 & 19 & $\mathrm{x}$ & - \\
\hline Permethrin & I & Pyrethroid & $\mathrm{CT}$ & $\mathrm{R}$ & 1 & 4 & $\mathrm{x}$ & $\mathrm{x}$ \\
\hline Phenthoate & I & Organophosphorus & TG & $\mathrm{R}$ & 1 & 3 & $\mathrm{x}$ & $\mathrm{x}$ \\
\hline Pretilachlor & $\mathrm{H}$ & Chloroacetanilide & CT, TG & R, RIPM, RF, RFIPM & 21 & 49 & - & - \\
\hline Propiconazole & $\mathrm{F}$ & Azole & CT, TG & R, RIPM, RF, RFIPM & 20 & 53 & $\mathrm{x}$ & - \\
\hline $\begin{array}{l}\text { Pyrazosulfuron } \\
\text { ethyl }\end{array}$ & $\mathrm{H}$ & Sulfonylurea & TG & $\mathrm{R}, \mathrm{RF}$ & 2 & 6 & $\mathrm{x}$ & - \\
\hline Quinalphos & I & Organophosphorus & $\mathrm{CT}$ & $\mathrm{R}, \mathrm{RF}$ & 3 & 6 & $\mathrm{x}$ & $\mathrm{x}$ \\
\hline Quinclorac & $\mathrm{H}$ & Unclassified & TG & $\mathrm{R}, \mathrm{RF}$ & 2 & 5 & $\mathrm{x}$ & - \\
\hline Thiamethoxam & I & Neonicotinoid & $\mathrm{CT}$ & R, RIPM, RF, RFIPM & 16 & 54 & $\mathrm{x}$ & - \\
\hline Tricyclazole & $\mathrm{F}$ & Azole & TG & RFIPM & 2 & 6 & $\mathrm{x}$ & - \\
\hline Validamycin & $\mathrm{F}$ & Antibiotic & CT, TG & R, RIPM, RF & 6 & 14 & - & - \\
\hline
\end{tabular}

${ }^{\text {a }} I$ insecticide, $H$ herbicide, $F$ fungicide

${ }^{\mathrm{b}}$ From PAN Pesticide Database (2014)

${ }^{\mathrm{c}} C T$ Can Tho, $T G$ Tien Giang

${ }^{\mathrm{d}} R$ rice farming, $R I P M$ rice farming with integrated pest management training, $R F$ rice-fish farming, $R F I P M$ rice-fish farming with IPM training

${ }^{\mathrm{e}}$ Single pesticide application, input data in PRIMET

${ }^{\mathrm{f}}$ Fenclorim (herbicide safener) is a mixture with pretilachlor (Sofit)

narrowed down to only include fish families of fish cultivated in the Mekong Delta. Only freshwater lab tests with $\mathrm{LC}_{50}$ values or $\mathrm{EC}_{50}$ values for immobility were used, with test duration of 2-21 days for fish and 1-7 days for arthropods, and EC50 values for biomass or growth for algae with 17 days of exposure time (Maltby et al. 2005).

$\mathrm{EC}_{50}$ and $\mathrm{LC}_{50}$ data were compiled from single-species aquatic toxicity tests including both static and flowthrough tests and were log-transformed according to
Raimondo et al. (2009). SSDs were computed with the software ETX 2.0 (Van Vlaardingen et al. 2003). The geometric means of $\mathrm{EC}_{50}$ and $\mathrm{LC}_{50}$ concentrations $(\mu \mathrm{g} / \mathrm{L})$ per species (if several tests) were inserted into the ETX software for each substance. The data points were then fitted to a log normal distribution model. The model fit was tested using the Anderson-Darling goodness-of-fit test with $\alpha=0.05$ as a critical level. A hazardous concentration $\left(\mathrm{HC}_{5}\right.$ and $\left.\mathrm{HC}_{50}\right)$ affecting 5 , 
Table 4 The active ingredients assessed by PRIMET, with acute and chronic ETRs, PEC, and PNEC values

\begin{tabular}{llcll}
\hline Active ingredient & $\mathrm{PEC}_{n}$ water $(\mu \mathrm{g} / \mathrm{L})$ & $\mathrm{PNEC}_{\text {water-acute }}(\mu \mathrm{g} / \mathrm{L})$ & $\mathrm{ETR}_{n \text { water-acute }}$ & $\mathrm{ETR}_{n \text { water-chronic }}$ \\
\hline Alpha-cypermethrin & $33.88-400.2$ & 0.002821 & $12,000-142,000$ & $623-7,366$ \\
Buprofezin & $1.91-55.46$ & 3.3 & $0.58-25.55$ & $0.16-7.29$ \\
Butachlor & $69.96-349.8$ & 4.4 & $15.9-79.5$ & - \\
Diazinon & $58.37-116.7$ & 0.01 & $5,837-11,700$ & $0.2-0.4$ \\
Ethoxysulfuron & $35.27-86.69$ & 19 & $1.85-4.56$ & $0.01-0.02$ \\
Etofenprox & $16.73-351.2$ & 0.012 & $1,394-29,300$ & $17.64-370.5$ \\
Fenclorim & $4.19-93.26$ & 6 & $0.70-15.54$ & - \\
Fenobucarb & $5.8-652.4$ & 1 & $5.8-652.4$ & - \\
Fenoxaprop-P-ethyl & $111.2-270.9$ & 1.9 & $58.55-142.6$ & $0.01-0.09$ \\
Fipronil & $92.37-325.6$ & 1.9 & $48.62-171.4$ & $11.26-39.69$ \\
Glyphosate & 25.68 & 380 & 0.07 & 0.007 \\
Hexaconazole & $58.88-961.4$ & 29 & $2.03-33.15$ & - \\
Imidacloprid & $7.5-302.8$ & 853 & $0.01-0.36$ & $0.01-0.29$ \\
Iprodione & $14.57-43.72$ & 6.6 & $2.21-6.63$ & $0.33-0.99$ \\
Isoprothiolane & $77.69-333.2$ & 68 & $1.14-4.9$ & - \\
Permethrin & $97.48-146.2$ & 0.006 & $16,300-24,400$ & $5,090-7,635$ \\
Phenthoate & 52.24 & 0.017 & 3,073 & - \\
Propiconazole & $8.69-181.2$ & 9 & $0.96-20.13$ & $0.27-5.72$ \\
Pyrazosulfuron ethyl & $18.22-22.62$ & 1,800 & 0.01 & - \\
Quinalphos & $36.04-108.1$ & 0.0066 & $5,461-16,380$ & $34.19-102.6$ \\
Quinclorac & $87.68-109.7$ & 298 & $0.29-0.36$ & - \\
Thiamethoxam & $36.78-367.8$ & 1,000 & $0.04-0.37$ & $0.00-0.03$ \\
Tricyclazole & 44.06 & 73 & 0.6 & 0.45 \\
\hline & & & & \\
\end{tabular}

ETR values are classified as $<1=$ "no risk," $1-100=$ "possible risk," and $>100=$ "definite risk" based on worstcase assumptions preset by PRIMET respectively, $50 \%$ of the species under consideration was then obtained. The $\mathrm{PEC}_{1}$ from PRIMET (one single pesticide application) was used to estimate the exposure to the pesticides and provided a basis to calculate a PAF, based on the rice farmers' pesticide use. Unlike the ETR quotients that are based on $\mathrm{PEC}_{n}$ values, $\mathrm{PEC}_{1}$ values were chosen for PAF calculations as they represent the environmental concentration of a single pesticide application, which was assessed to best correspond with the acute toxicity test that the SSDs are based on. The majority of the scenarios in PRIMET, however, only included one application. For the calculations of the PAFs, maximum and average concentrations per management regime and per province were used (Table 6).

\section{Comparison of risks between different management regimes and provinces}

In order to get a more general comparison of the aquatic risk caused by the farming types and between the two provinces, annual ETR values were calculated for each type. Annual ETR values were calculated by adding up all individual ETR values from each pesticide application during all the crops in
1 year (two to three crops/year) in one rice field. For farmers with more than one rice field, an average for all rice fields was calculated, as the variation between rice fields of one farmer in comparison to variation between farmers was negligible. The total amount of applied pesticides per year was calculated the same way.

\section{Statistics}

In order to test if there were statistical differences in the amount of pesticides used ( $\mathrm{kg}$ A.I./ha) and in the risk to aquatic organisms (ETR values) between the two provinces and the management types, data was compared using ANOVA with a $2^{3}$ factorial design with province, $I P M$, and fish as fixed factors and active ingredient $(\mathrm{g} / \mathrm{ha})$ and ETR values as dependent variables. Data was logtransformed to create a better fit to a normal distribution, and the significance level for all tests was set to $\alpha=0.05$. Homogeneity of variance was tested with an $F$ test. Nonparametric Kruskal-Wallis tests were used on data that had large variance (e.g., ETR comparison between provinces). Statistics were calculated using R (version 3.1.2). 


\section{Results}

\section{ETRs}

ETR values could be calculated for 28 of the active ingredients, of which 13 were insecticides, 9 herbicides, and 6 fungicides. Five pesticides (bensulfuron-methyl, cartap, isoprocarb, pretilachlor, and validamycin) identified in the interviews could not be assessed with PRIMET, due to missing physico-chemical parameters in published literature and current databases, and were therefore not included in the analysis (Table 3). Pretilachlor was the most commonly used herbicide among the farmers (21 users), which often was found in a mixture with a herbicide safener, fenclorim.

Active ingredients that generated no or low risk to aquatic organisms $($ ETR $<1)$ were the insecticides imidacloprid and thiamethoxam, the herbicides pyrasulfuron ethyl and quinclorac, and the fungicide tricyclazole. A possible risk (ETR 1-100) was found for the insecticide buprofezin; the herbicides butachlor, ethoxysulfuron, and fenclorim (herbicide safener); and the fungicides hexaconazole, iprodione, isoprothiolane, and propiconazole. Hexaconazole was the most commonly used fungicide among the farmers with 43 users and a total of 113 applications (15\% of all applications) (Table 3 ).

High-risk pesticides, i.e., substances generating ETR values $>100$, were the insecticides, alpha-cypermethrin, diazinon, etofenprox, fenobucarb, fipronil, permethrin, phenthoate, quinalphos, and the herbicide fenoxaprop-P-ethyl, indicating a high risk for acute toxicity to aquatic organisms for these compounds at the predicted concentrations in rice paddies. The pyrethroids alpha-cypermethrin and permethrin also had high ETR values in the chronic assessment, while the chronic risk quotients for diazinon and fenoxaprop-P-ethyl were below 1. For fipronil, the chronic ETR values were lower than 100 but still constituted a possible risk. A chronic ETR value could not be calculated for fenobucarb and phenthoate due to missing input parameters (Table 4). Fenobucarb was the most commonly used insecticide in the study with a total of 55 users in both provinces. Out of the 154 application scenarios with fenobucarb (20\% of all applications) (Table 3), 124 (80\%) generated risk values above 100. For alpha-cypermethrin, diazinon, etofenprox, permethrin, phentoate, and quinalphos, all application scenarios generated acute ETR values above 100. For fipronil, 9 out of 17 application scenarios generated risk values above 100 and for the herbicide fenoxaprop-P-ethyl, 5 out of 8 . In total, insecticides made up almost $50 \%$ of all application scenarios, of which $58 \%$ generated a risk value above 100 .

\section{SSDs}

Species sensitivity distributions were calculated for all substances, which generated ETR values above 100, except for the herbicide fenoxaprop-P-ethyl, which was excluded from further analysis, as there was too little algal toxicity data available for this substance.

The results indicate that the pyrethroids alphacypermethrin, etofenprox, and permethrin are the substances that are most likely to cause toxic effects on fish, with $\mathrm{HC}_{5} /$ $\mathrm{HC}_{50}$ of $0.57 / 5.51,0.91 / 282.95$, and $0.95 / 8.19 \mu \mathrm{g} / \mathrm{L}$, respectively. These were followed by phenthoate, fipronil, quinalphos, diazinon, and fenobucarb in descending order of toxicity (Table 5). For arthropods, the same insecticides were assessed, except for quinalphos, where too little toxicity data was available. Here, the pyrethroids permethrin and alphacypermethrin displayed the highest toxicity with $\mathrm{HC}_{5} / \mathrm{HC}_{50}$ of $0.0084 / 1.24$ and $0.0085 / 3.11 \mu \mathrm{g} / \mathrm{L}$, respectively, and fipronil $0.037 / 1.77 \mu \mathrm{g} / \mathrm{L}$. The SSDs for fenobucarb and phentoate were only based on three data points each; hence, results should be cautiously interpreted, although phenthoate had the lowest $\mathrm{HC}_{5}$ value. Overall, all the insecticides were more toxic to arthropods than to fish.

Rice farmers, without fish, generally used more toxic compounds generating higher PAF values compared to rice-fish farmers (Table 6). For the less toxic substance fenobucarb and fipronil, these patterns were not as clear, although rice-fish farmers applying IPM had a somewhat lower PAF for fipronil compared to the other farmers. Fenobucarb had the lowest estimated fish toxicity and relatively low PAF compared to the other substances (Table 5 and 6). Alpha-cypermethrin had a PAF of more than $95 \%$ for all farmer groups, indicating that almost all fish species could be affected by the use of this insecticide. Thus, the use of alpha-cypermethrin probably poses a high risk to fish (PAN 2014; Lewis et al. 2016), but the results should be interpreted somewhat carefully as the SSD is only based on six data points (Table 5). Similarly, the SSD for fipronil was generated using five data points only. The calculated risks do not include application over seasons or the combined toxicity of multiple pesticides (i.e., mixture toxicity). Except for permethrin and alpha-cypermethrin (where more than $90 \%$ of the fish species were affected), the PAF of arthropods was noticeably higher than that of fish, indicating that a larger fraction of arthropod species compared to fish species were affected by the PECs of the study.

\section{Comparison of risks between different farming strategies and provinces}

Average amount of applied active ingredients $(\mathrm{g} / \mathrm{ha})$ and average acute ETR values in each province and for each farming type are presented in Fig. 3. Only pesticides that could be evaluated by PRIMET are included. Farmers in Tien Giang used significantly higher amount of active ingredients (1.5 times more) than farmers in Can Tho. There were, however, no significant differences between the $\log$ (ETR) data. Due to a significant difference in variance between provinces for log (ETR) values ( $F$ test, $\alpha=10^{-8}$ ), the log-transformed ETR data 
Table $5 \mathrm{HC}_{5}$ and $\mathrm{HC}_{50}$ concentrations to fish and arthropods calculated from species sensitivity distributions for the insecticides with ETR values $>100$

\begin{tabular}{|c|c|c|c|c|c|c|}
\hline Active ingredient & $\begin{array}{l}\text { Fish } \\
\text { No. of data } \\
\text { points }^{\mathrm{a}}\end{array}$ & $\mathrm{HC}_{5}(\mu \mathrm{g} / \mathrm{L})$ & $\mathrm{HC}_{50}(\mu \mathrm{g} / \mathrm{L})$ & $\begin{array}{l}\text { Arthropod } \\
\text { No. of data } \\
\text { points }^{\mathrm{a}}\end{array}$ & $\mathrm{HC}_{5}(\mu \mathrm{g} / \mathrm{L})$ & $\mathrm{HC}_{50}(\mu \mathrm{g} / \mathrm{L})$ \\
\hline Alpha-cypermethrin & 6 & $0.57(0.05-1.77)$ & $5.51(1.90-15.99)$ & 5 & $0.0085(0.00000274-0.21)$ & $3.11(0.31-73.52)$ \\
\hline Diazinon & $20^{\mathrm{b}}$ & $505.4(221-890.8)$ & $3403(2189-5291)$ & 25 & $0.48(0.18-0.95)$ & $6.30(3.70-10.74)$ \\
\hline Etofenprox & 7 & $0.91(0.00-13.44)$ & $282.95(24.88-3218.48)$ & 12 & $0.058(0.0015-0.52)$ & $21.01(3.44-128.3)$ \\
\hline Fenobucarb & 7 & $570.6(97.42-1349)$ & 3577 (1642-7792) & 3 & $1.14(0.00028-7.47)$ & $18.89(1.64-217.9)$ \\
\hline Fipronil & 5 & $37.72(4.83-85.22)$ & $170.46(75.97-382.50)$ & 29 & $0.037(0.0099-0.1)$ & $1.77(0.85-3.71)$ \\
\hline Permethrin & 16 & $0.95(0.5-1.92)$ & $8.19(4.66-14.38)$ & 54 & $0.0084(0.0026-0.02)$ & $1.24(0.62-2.47)$ \\
\hline Phenthoate & 10 & $4.69(0.48-17.12)$ & $117.17(39.16-350.55)$ & 3 & $\begin{array}{c}0.0056 \\
(0.0000000000039-0.67)\end{array}$ & $\begin{array}{c}7.07 \\
(0.014-0.0035)\end{array}$ \\
\hline Quinalphos & 11 & $120.3(35.2-246.9)$ & $774.8(425.1-1412)$ & - & - & - \\
\hline
\end{tabular}

Values in brackets are the confidence intervals

${ }^{a}$ No of data points indicate the number of species used in each SSD

${ }^{\mathrm{b}}$ Data did not pass the Anderson-Darling test on log-normality at the 5\% level, but at $2.5 \%$

was instead tested with a non-parametric Kruskal-Wallis test, in order to see if there were any effects of the management regimes within each province. The test did not reveal any significant differences between management regimes, $\alpha=0.97$ (Can Tho) and $\alpha=0.16$ (Tien Giang), and hence, no statistical differences for average ETR could be detected, although there was a trend indicating that rice-fish farmers generally showed a lower risk in their choice and use of pesticides as compared to rice farmers and that IPM farmers generally had a lower risk than non-IPM farmers in Can Tho, where the risks were more pronounced (Fig. 3b). Similar results were seen when comparing the maximum ETR values between different management regimes and areas.

\section{Discussion}

An advantage of using the PRIMET model is that it requires fairly low input of data to make a first-tier risk estimate for different pesticides (Ansara-Ross et al. 2008; Malherbe et al. 2013). This kind of first-tier screening model was therefore seen as suitable method for this study, which dealt with a large set of data of farmers' pesticide applications under different management regimes and aimed at comparing risks of different pesticide uses to aquatic organisms.

However, it should be noted that the methodology used by PRIMET underestimates the risks with neonicotinoids to freshwater arthropods due to Daphnias' low sensitivity (PNEC $853 \mu \mathrm{g} / \mathrm{L}$ ). Other arthropods such as the nymphs of mayflies have proven to be much more sensitive to imidacloprid (Roessink et al. 2013; Van den Brink et al. 2016). A study evaluating if acute first- and second-tier approaches recommended by the European Food Safety Authority (EFSA) have a sufficient degree of protection for different insecticide groups also concludes that neonicotinoids need to be further assessed as some of the approaches used were underprotective for a few substances (Van Wijngaarden et al. 2015). Therefore, the results of neonicotinoids for this study should be interpreted with caution.

The species sensitivity distribution model was chosen primarily to include risks to fish, as fish are generally underrepresented in other higher-tier models, such as the PERPEST model, based on microcosm and mesocosm studies (Van den Brink et al. 2002). SSD is, however, based on single-species tests, for one pesticide at the time, and does not take into account species interactions, indirect effects between species, and toxicity of pesticide mixtures. Still, risk assessment based on SSDs has been shown to be good first-tier risk assessment of acute risks of pesticides to aquatic organisms (e.g., Maltby et al. 2005; Van den Brink et al. 2006; Maltby et al. 2009).

The risk assessment (i.e., ETR values to aquatic organisms) revealed a different pattern than what was detected from only studying the amounts of applied active ingredients (Fig. 3). In Tien Giang, farmers applied on average 1.5 more active ingredients per hectare than in Can Tho. The risks, however, appear to be higher in Can Tho. This is because the farmers in Tien Giang used pesticides, which are less toxic to aquatic organisms, such as a carbamate (fenobucarb), while the farmers in Can Tho used several insecticides, which have a high acute toxicity such as pyrethroids (alpha-cypermethrin, permethrin, 
Table 6 The highest and average predicted environmental concentrations (PECs) per insecticide and management regime (provinces CT = Can Tho; $\mathrm{TG}=$ Tien Giang) and their associated potentially affected fraction (PAF) with confidence interval and standardized log concentration, calculated from the SSDs presented in Table 5

\begin{tabular}{|c|c|c|c|c|c|c|}
\hline \multirow[t]{2}{*}{ Active ingredient } & \multirow[t]{2}{*}{ Management } & \multirow{2}{*}{$\begin{array}{l}\text { Maximum } \\
\quad \text { PEC1 }(\mu \mathrm{g} / \mathrm{L})\end{array}$} & \multicolumn{2}{|l|}{ Fish } & \multicolumn{2}{|l|}{ Arthropod } \\
\hline & & & Median PAF (\%) & $\begin{array}{l}\text { Standard log } \\
\text { concentration }\end{array}$ & Median PAF (\%) & $\begin{array}{l}\text { Standard log } \\
\text { concentration }\end{array}$ \\
\hline \multirow[t]{4}{*}{ Alpha-cypermethrin } & CT-R & 400.2 & $99.90(92.51-100)$ & 3.31 & $91.26(62.07-99.40)$ & 1.46 \\
\hline & CT-RF & 80.04 & 97.38 (78-99.94) & 4 & $81.91(50.65-96.80)$ & 0.98 \\
\hline & CT-RIPM & 160.1 & $99.26(85.70-100)$ & 4.88 & $86.52(55.81-98.36)$ & 1.19 \\
\hline & CT-RFIPM & 53.36 & 95.03 (72.32-99.77) & 3.48 & $79.24(47.94-95.66)$ & 0.87 \\
\hline \multirow[t]{2}{*}{ Diazinon } & CT-R & 116.7 & $0.18(0.01-1.92)$ & -2.96 & $96.79(90.50-99.22)$ & 1.87 \\
\hline & CT-RF & 58.37 & $0.02(0.00-0.58)$ & -3.56 & $92.10(82.83-97.07)$ & 1.43 \\
\hline \multirow[t]{3}{*}{ Etofenprox } & CT-R & 351.2 & $52.49(28.77-75.34)$ & 0.07 & $78.43(59.51-91)$ & 0.81 \\
\hline & CT-RIPM & 117.1 & $39.93(18.68-64.75)$ & -2.67 & $68.47(49.10-83.81)$ & 0.49 \\
\hline & CT-RFIPM & 16.73 & $20.74(16-46.47)$ & -0.85 & $47.46(29.49-65.97)$ & -0.07 \\
\hline \multirow[t]{8}{*}{ Fenobucarb } & CT-R & 418.2 & $2.74(0.11-19.67)$ & -2.03 & $96.46(56.52-99.99)$ & 2.14 \\
\hline & CT-RF & 434.9 & $2.96(0.09-20.29)$ & -1.99 & 96.64 (56.89-99.99) & 2.16 \\
\hline & CT-RIPM & 290 & $1.23(0.06-14.49)$ & -2.37 & $94.51(52.96-99.98)$ & 1.88 \\
\hline & CT-RFIPM & 241.6 & $0.8(0-12.32)$ & -2.54 & $93.26(51.09-99.96)$ & 1.76 \\
\hline & TG-R & 362.4 & $2.02(0.12-17.5)$ & -2.16 & $95.78(55.16-99.99)$ & 2.04 \\
\hline & TG-RF & 652.4 & $6.35(-0.09-27.59)$ & -1.61 & $98.03(60.54-100)$ & 2.44 \\
\hline & TG-RIPM & 362.4 & $2.02(0.12-17.5)$ & -2.16 & $95.78(55.16-99.99)$ & 2.04 \\
\hline & TG-RFIPM & 420.6 & $2.77(0.11-19.76)$ & -2.02 & 96.49 (56.58-99.99) & 2.14 \\
\hline \multirow[t]{4}{*}{ Fipronil } & CT-R & 233.1 & $63.54(33.85-86.69)$ & 0.37 & $98.10(93.86-99.57)$ & 2.10 \\
\hline & CT-RF & 233.1 & $63.54(33.85-86.69)$ & 0.37 & $98.10(93.86-99.57)$ & 2.10 \\
\hline & CT-RIPM & 224.1 & $61.89(32.48-85.57)$ & 0.32 & $98.02(93.69-99.54)$ & 2.08 \\
\hline & CT-RFIPM & 194.2 & $55.73(27.53-81.20)$ & 0.15 & $97.70(93.04-99.44)$ & 2.02 \\
\hline Permethrin & CT-R & 146.2 & 98.6 (92.48-99.87) & 2.24 & $94.17(88.94-97.28)$ & 1.58 \\
\hline Phenthoate & TG-R & 52.24 & $33.90(16.82-55.14)$ & -0.43 & $68.30(29.19-93.60$ & 0.54 \\
\hline \multirow[t]{2}{*}{ Quinalphos } & CT-R & 108.1 & $4.1(0.47-17.15)$ & -1.79 & - & - \\
\hline & CT-RF & 36.04 & $0.34(0.01-5.15)$ & -2.79 & - & - \\
\hline \multirow[t]{2}{*}{ Active ingredient } & Management & $\begin{array}{l}\text { Average } \\
\quad \text { PEC1 }(\mu \mathrm{g} / \mathrm{L})\end{array}$ & Fish & & Arthropod & \\
\hline & & & Median PAF (\%) & $\begin{array}{l}\text { Standard log } \\
\text { concentration }\end{array}$ & Median PAF (\%) & $\begin{array}{l}\text { Standard log } \\
\text { concentration }\end{array}$ \\
\hline \multirow[t]{4}{*}{ Alpha-cypermethrin } & CT-R & 285.86 & $99.79(99.4-100)$ & 3.05 & $89.69(59.84-99.13)$ & 1.36 \\
\hline & CT-RF & 70.04 & $96.74(76.23-99.91)$ & 1.96 & $80.92(49.62-96.39)$ & 0.94 \\
\hline & CT-RIPM & 100.19 & $98.22(80.76-99.97)$ & 2.24 & $84.10(53.02-97.61)$ & 1.07 \\
\hline & CT-RFIPM & 48.02 & $94.20(70.70-99.67)$ & 1.67 & $78.14(46.85-95.16)$ & 0.83 \\
\hline \multirow[t]{2}{*}{ Diazinon } & CT-R & 116.7 & $0.18(0.01-1.92)$ & -2.96 & $96.79(90.50-99.22)$ & 1.87 \\
\hline & CT-RF & 58.37 & $0.02(0.00-0.58)$ & -3.56 & $92.10(82.83-97.07)$ & 1.43 \\
\hline \multirow[t]{3}{*}{ Etofenprox } & CT-R & 292.7 & $50.39(27.03-73.62)$ & 0.01 & $76.92(57.85-89.98)$ & 0.75 \\
\hline & CT-RIPM & 88.79 & $36.87(16.38-62.04)$ & -0.35 & $65.77(46.44-81.67)$ & 0.42 \\
\hline & CT-RFIPM & 16.73 & $20.74(16-46.47)$ & -0.85 & $47.46(29.49-65.97)$ & -0.07 \\
\hline \multirow[t]{7}{*}{ Fenobucarb } & CT-R & 340.73 & $1.77(0.11-16.63)$ & -2.22 & $95.46(54.56-99.99)$ & 1.99 \\
\hline & CT-RF & 187.7 & $0.42(0.00-9.75)$ & -2.78 & $92.52(50.09-99.94)$ & 1.69 \\
\hline & CT-RIPM & 161.49 & $0.28(0.00-8.43)$ & -2.92 & $89.72(46.73-99.79)$ & 1.48 \\
\hline & CT-RFIPM & 186.4 & $0.41(0.00-9.68)$ & -2.79 & $91.11(48.32-99.88)$ & 1.58 \\
\hline & TG-R & 138.75 & $0.19(0.00-7.24)$ & -3.07 & 88.39 (45.31-99.70) & 1.39 \\
\hline & TG-RF & 175.43 & $0.35(0.00-9.14)$ & -2.85 & 91.39 (48.65-99.89) & 1.60 \\
\hline & TG-RIPM & 154.75 & $0.25(0.00-8.08)$ & -2.96 & $89.28(46.25-99.77)$ & 1.45 \\
\hline
\end{tabular}


Table 6 (continued)

\begin{tabular}{lllllll}
\hline \multirow{2}{*}{ Fipronil } & TG-RFIPM & 223.4 & $0.66(0.00-11.47)$ & -2.62 & $93.44(51.34-99.96)$ & 1.77 \\
& CT-R & 230.1 & $63(33.40-86.33)$ & 0.35 & $98.07(93.81-99.56)$ & 2.09 \\
& CT-RF & 145.69 & $43.10(17.96-71.55)$ & -0.19 & $96.95(91.58-99.16)$ & 1.89 \\
Permethrin & CT-RIPM & 186.73 & $54.02(26.19-79.93)$ & 0.11 & $97.61(92.86-99.40)$ & 2.00 \\
Phenthoate & CT-RFIPM & 153.53 & $45.39(19.63-73.35)$ & -0.12 & $97.10(91.87-99.22)$ & 1.92 \\
Quinalphos & CT-R & 121.84 & $98.02(90.86-99.77)$ & 2.1 & $93.44(87.91-96.83)$ & 1.52 \\
& TG-R & 52.24 & $33.90(16.82-55.14)$ & -0.43 & $68.30(29.19-93.60$ & 0.54 \\
& CT-R & 96.09 & $3.27(0.32-15.31)$ & -1.9 & - & - \\
\hline
\end{tabular}

etofenprox) and the organophosphates diazinon and quinalphos. Thus, the difference in ETR values between Can Tho and Tien Giang observed here shows that it is not only the amount of A.I. that is important to consider when evaluating potential risks by different pesticides to aquatic organism but also to compare the intrinsic properties of the different pesticides such as their toxicity, persistence, and lipophilicity.

The ETR data also indicate that rice-fish farmers in Can Tho used lower amounts of high-risk pesticides than rice farmers. Also, farmers with IPM training chose less toxic pesticides, compared to non-IPM farmers, which has previously been shown among Asian farmers (FAO 2013). A previous study showed that rice-fish farmers tend to be more aware of the possible negative side effects from pesticides on fish and therefore select less toxic pesticides (Berg and Tam 2012). This is confirmed by the results of this study, where the PAFs of fish from pesticides were generally lower among fish farmers compared to farmers only growing rice. Fenobucarb was, however, an exception, most likely due to its relative low toxicity to fish. Fenobucarb is also one the most popular insecticides among the farmers, probably due to its efficiency against pests, price, and marketing (Berg and Tam 2012).
PECs can be assumed to be somewhat higher than measured concentrations in the field due to worst-case assumptions. It is also important to remember that they represent peak water concentrations after application, something that is seldom captured in monitoring studies. Still, the predicted average peak concentrations of this study (PEC is 139-341 $\mu \mathrm{g} / \mathrm{L}$ for fenobucarb under different management regimes; Table 6) correspond well with measured fenobucarb concentrations in an experimental rice field $1 \mathrm{~h}$ after application (127 $\mu \mathrm{g} / \mathrm{L})$ (Tam et al. 2016a). The measured concentrations of fenobucarb were found after application using a dose commonly used by farmers in the area. Another study investigating field exposure of diazinon to fish after farmers' normal practice in the Mekong Delta found diazinon concentrations of $130-170 \mu \mathrm{g} / \mathrm{L}$ $1 \mathrm{~h}$ after exposure (Cong et al. 2008). This is somewhat higher than the PECs of this study (PEC is 58.37-116.7 for diazinon under different management regimes; Table 6).

Overall, the potential affected fraction was quite high and indicates that fish may be at risk from the high pesticide use in the Mekong Delta. Aquatic organisms living in the rice fields are probably continuously exposed to elevated levels of many different pesticides
Fig. 3 a Average applied active ingredients (g/ha) and $\mathbf{b}$ average acute ETR values calculated for the unit rice field for the two provinces Can Tho and Tien Giang. Error bars show the standard errors of the mean per province and management regime

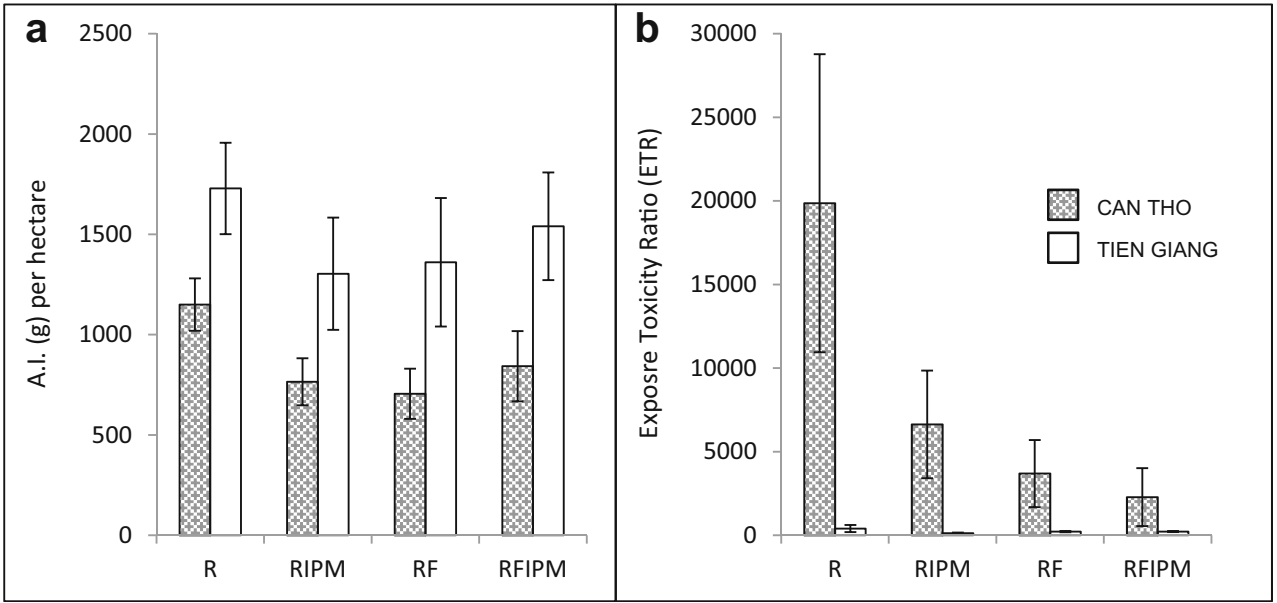


during their entire life cycles because rice farming is applied throughout the year (Toan et al. 2013; Tam et al. 2016b). In addition, pesticides are easily spread to other areas through spray drift and irrigation channels, exposing organisms to a variety of different pesticides.

Although the estimated PAFs are based on worst-case scenarios, the toxicity data used to generate the SSDs for fish are based on $\mathrm{LC}_{50}$ studies, thus indicating severe impacts on the fish. It is likely that also, lower concentrations than those used in the worst-case scenarios would cause sub-lethal effects in fish. For example, Tam et al. (2015a) showed that that low levels of fenobucarb $(30 \mu \mathrm{g} / \mathrm{L})$ and chlorphyrifos $(0.5 \mu \mathrm{g} / \mathrm{L})$ caused a significant inhibition of brain AChE activity in climbing perch, causing both decreased growth and survival rates in the fish. Also, at lower concentrations, freshwater arthropods, which have been shown to have a higher sensitivity to the investigated insecticides, are affected, thereby indirectly affecting the fish, as these usually are complementary food for many fish species. The high PAFs of arthropods indicate that there also could be other serious effects on ecosystem functioning, such as decreased amount of natural predators to pest organisms. Microcosm and mesocosm studies of the investigated substances were rare, and only studies evaluating diazinon, etofenprox, and permethrin were found. For diazinon, PEC values of 58.37-116.7 $\mu \mathrm{g} / \mathrm{L}$ (Table 4) can be compared to a calculated community NOEC of $4.3 \mu \mathrm{g} / \mathrm{L}$ (Giddings et al. 1996) and for etofenprox PEC values in the range of $16.73-351.2 \mu \mathrm{g} / \mathrm{L}$ (Table 4) to a community NOEC of $2 \mu \mathrm{g} / \mathrm{L}$ (Blake 2004). For permethrin, a reduction of diversity in zooplankton communities was noticed at $0.5 \mu \mathrm{g} / \mathrm{L}$ (Kaushik et al. 1985), which is much lower than the PECs of $97.48-146.2 \mu \mathrm{g} / \mathrm{L}$ found in this study.

The calculated risk from pesticide use found both from the SSD and the PRIMET models indicate high risks for aquatic organisms including fish, despite the fact that the models do not account for repeated application of pesticides (the fish are often stocked during two to three crops) or additive toxicity of substances applied together (toxicity from pesticide mixtures). Some of the pesticides identified from the interviews were also omitted from the analyses due to insufficient current knowledge on their toxic properties.

The aquaculture industry is currently expanding rapidly in the delta (De Silva and Phuong 2011) with increasing demands for a good water quality and healthy food products. The high use of pesticides in rice farming probably creates sub-optimal conditions for integrated rice-fish farming and may have negative implications for a sustained and healthy production of fish in the delta. The pesticide market in Vietnam has expanded during the last 10 years, and it is a challenge for the country's large number of small-scale farmers to find appropriate technical advice from, e.g., retailers (Hoi et al. 2016), on a safe use of new pesticides. A group of pesticides that has steadily increased over the period of 1999-2013 (Hoi et al. 2016) falls under the classification II-moderately toxic (WHO 2010). Most of the substances with the highest toxicity of this study are included in that category. To reduce risks among farmers in the future, several policy options should be considered together, such as reducing pesticide supply, developing monitoring of pesticide risks in combination with lowering pesticide demand through, e.g., farmer field training (Schreinemacher et al. 2015).

Even though the use of PRIMET for probabilistic risk assessments is a good first step, there is a need to conduct further risk assessments in the area based on site-specific measured environmental concentrations (MECs) to better assess the risks for aquatic organisms in the field. Still, by applying an easy-to-use approach, pesticides with lower predicted risk can be identified and preferred in management. Furthermore, the methodology identifies some priority substances that would be good to monitor in the field to further evaluate their risks to the environment.

\section{Conclusions}

Our study shows that farmers use a large number of pesticides likely to cause negative environmental effects on fish and other aquatic organisms. We therefore suggest that a screening model like PRIMET could provide a valuable tool to help provincial plant protection departments to select and recommend pesticides with potentially low environmental impacts and to substitute the pesticides that pose the highest risk with less toxic ones. Such screening models, with low data requirements, are especially relevant in developing countries, where field data are still scarce. Still, the lack of physico-chemical and toxicity data for some pesticides in this study was a problem and is something that needs to be further improved to make these kinds of first-order risk estimates operational in Vietnam and other developing countries. The combination of PRIMET with SSDs was a good way to assess fish toxicity based on PECs derived from interview data. Of highest concern for acute toxicity in this study were pyrethroids and a pyrazole pesticide and organophosphates. Farmers that had received IPM training and integrated rice-fish farmers often used pesticides with a lower risk compared to conventional rice farmers. Considering the increasing pesticide market and the large number of smallscale farmers in the country, governmental regulation of pesticides in combination with other strategies remain a key issue for reducing pesticide risks in the future. 
Acknowledgments Funding for this study was provided through faculty funding from Stockholm University. We would like to thank Marielle Andersson and Hanna Fues from the Department of Mathematics, Statistiska Forskningsgruppen, Stockholm University, for their assistance with statistical analyses. Furthermore, we would like to acknowledge two anonymous reviewers for their valuable comments on the manuscript.

Open Access This article is distributed under the terms of the Creative Commons Attribution 4.0 International License (http:// creativecommons.org/licenses/by/4.0/), which permits unrestricted use, distribution, and reproduction in any medium, provided you give appropriate credit to the original author(s) and the source, provide a link to the Creative Commons license, and indicate if changes were made.

\section{References}

Andrieu M, Rico A, Phu TM, Huong DTT, Phuong NT, Van den Brink PJ (2015) Ecological risk assessment of the antibiotic enrofloxacin applied to Pangasius catfish farms in the Mekong Delta, Vietnam. Chemosphere 119:407-414

Ansara-Ross TM, Wepener V, Van den Brink PJ, Ross MJ (2008) Probabilistic risk assessment of the environmental impacts of pesticides in the crocodile (west) Marico Catchment, North-West Province. Source Water SA 34(5):637-644

Berg H (2002) Rice monoculture and integrated rice-fish farming in the Mekong Delta, Vietnam. Ecol Econ 41:95-107

Berg H, Tam NT (2012) Use of pesticides and attitude to pest management strategies among rice and rice-fish farmers in the Mekong Delta, Vietnam. Int J Pest Manage 58(2):153-164

Berg H, Berg C, Nguyen TT (2012) Integrated rice-fish farming: safeguarding biodiversity and ecosystem services for sustainable food production in the Mekong Delta. J Sustain Agric 36:1-14

Blake N (2004). Assessment of the effects of etofenprox (MTI-500) on natural communities of freshwater organisms in outdoor mesocosms. Cambridge Environmental Assessment (CEA), Boxworth, Cambridgeshire, England (unpublished report no. XEC003). In Draft Assessment Report (DAR) (2007), ETOFENPROX, Volume 3, Annex B, part 5/A, B.9.

Bosma RH, Hanh CTT, Potting J (2009). Environmental impact assessment of the Pangasius sector in the Mekong Delta. Wageningen University, $50 \mathrm{pp}$.

Carvalho FP, Villeneuve JP, Cattini C, Tolosa I, Thuan DD, Nhan DD (2008) Agrochemical and polychlorobyphenyl (PCB) residues in the Mekong River Delta, Vietnam. Mar Poll Bull 56:1476-1485

Cao QN (2011). Evaluation of rotational rice-fish farming systems and new fish species for concurrent rice-fish culture in the Mekong Delta, Vietnam. Dissertation, Katholieke Universiteit, Leuven, The Netherlands.

Cong NV, Phuong NT, Bayley M (2008) Brain cholinesterase response in the snakehead fish (Channa striata) after field exposure to diazinon. Ecotoxicol Environ Saf 71:314-318

De Silva SS, Phuong NT (2011) Exploring the climate change concerns of striped catfish producers in the Mekong Delta, Vietnam. Rev Aquacult 3:45-73

De Zwart D (2002). Observed regularities in species sensitivity distributions for aquatic species. In: Posthuma L, Suter GW, Traas TP (eds) Species Sensitivity Distributions in Ecotoxicology. CRC Press LLC, pp 133-154.

Duong LT, Nahn DK, Rothius A, Quang PM, Giau TQ, Chi HH, Thuy LT, Hoa NV, Sinh LX (1998) Integrated rice-fish culture in the Mekong Delta of Vietnam: problems, constraints and opportunities for sustainable agriculture. In: Xuan V-T, Matsui S (eds) Development of farming Systems in the Mekong Delta of Vietnam
JIRCAS. Ho Chi Minh Publishing House, CTU \& CLRRI, pp. 235271

Duong LT, Can ND, Phan TT(2005). Current status of integrated cropanimal systems (ICAS) in Vietnam: a case study in the Mekong Delta. In: Sombilla MA, Hardy B, editors (2005). Integrated cropanimal systems in Southeast Asia: current status and prospects. IRRI Limited Proceedings No. 11. Los Baños (Philippines): International Rice Research Institute. $191 \mathrm{p}$.

FAO (2013) Empowering farmers to reduce pesticide risks, FAO regional IPM/pesticide risk reduction programme in Asia. FAO-RAP, Bangkok

General Statistics Office (2007) Results of the 2006 rural, agricultural and fishery census. Statistical Publishing House, Hanoi, Vietnam

General Statistics Office (2009) Statistical yearbook of Vietnam 2009. Statistical Publishing House, Hanoi, Vietnam

Giddings JM, Biever RC, Annuziato MF, Hosmer AJ (1996) Effects of diazinon on large outdoor pond microcosms. Environ Toxicol Chem 15(5):618-629

Hoa TTT, Minh TH, Phuong TV (2003). Part B: preliminary observations of the effects of water exchange on water quality, sedimentation rates and the growth and yields of Penaeus monodon in the riceshrimp culture system. In: Preston N, Clayton H (eds) Rice-shrimp farming in the Mekong Delta: biophysical and socioeconomic issues. ACIAR Technical Reports No. 52e.

Hoi PV, Mol APJ, Oosterveer P, Van den Brink PJ, Huong PTM (2016) Pesticide use in Vietnamese vegetable production: a 10-year study. Int J Agr Sustain. doi:10.1080/14735903.2015.1134395

Huan NH, Mai V, Escalada MM, Heong KL (1999) Changes in rice farmers' pest management in the Mekong Delta, Vietnam. Crop Prot 18:557-563

Huan NH, Chien HV, Quynh PV, Tan PS, Du PV, Escalada MM, Heong KL (2008) Motivating rice farmers in the Mekong Delta to modify pest management and related practices through mass media. Int $\mathrm{J}$ Pest Manage 54:339-346

Johnston RM, Hoanh CT, Lacombe G, Noble AN, Smakhtin V, Suhardiman D, Kam SP, Choo PS (2010) Rethinking agriculture in the greater Mekong subregion: how to sustainably meet food needs, enhance ecosystem services and cope with climate change. International Water Management Institute, Colombo, Sri Lanka, 26p. doi: $10.3910 / 2010.207$

Kaushik NK, Stephenson CL, Solomon KR, Day KE (1985) Impact of permethrin on zooplankton communities in lirnnocorrals. Can J Fish Aquat Sci 42:77-85

Lewis KA, Tzilivakis J, Warner D, Green A (2016) An international database for pesticide risk assessments and management. Hum Ecol Risk Assess. doi:10.1080/10807039.2015.1133242

$\mathrm{Lu}$ J, Li X (2006) Review of rice-fish-farming systems in China - one of the globally important ingenious agricultural heritage systems (GIAHS). Aquaculture 260:106-113

Malherbe W, Van Vuren JHJ, Wepener V (2013) Preliminary risk assessment of common-use pesticides using PRIMET and PERPEST pesticide risk models in a semi-arid subtropical region. Water SA 39(5). doi:10.4314/wsa.v39i5.3

Maltby L, Blake N, Brock TCM, Van den Brink PJ (2005) Insecticide species sensitivity distributions: importance of test species selection and relevance to aquatic ecosystems. Env Tox Chem 24(2):379-388

Maltby L, Brock TCM, Van den Brink PJ (2009) Fungicide risk assessment for aquatic ecosystems: importance of interspecific variation, toxic mode of action, and exposure regime. Environ Sci Technol 43: 7556-7563

Nga NTT, Sinh LX (2008) Economic efficiency and technical aspects of rice-fish and mono-rice systems in O Mon-Xa no irrigation project. Scientific Journal of Cantho University 2:176-187

Nhan DK, Phong LT, Verdegem MCJ, Duong LT, Bosma RH, Little DC (2007) Integrated freshwater aquaculture, crop and livestock 
production in the Mekong Delta, Vietnam: determinants and the role of the pond. Agric Syst 94:445-458

PAN Pesticide Database (2014). http://www.pesticideinfo.org/. Accessed 2014-12-01.

Peeters FM, Van den Brink PJ, Vlaming J, Groenwold JG, Beltman WHJ, Boesten JJTI (2008). PRIMET version 2.0, manual and technical description. A Decision Support System for assessing Pesticide Risks in the tropics, to Man, Environment and Trade. Wageningen, Alterra, Alterra rapport 1648.

Phan LT, Tam BM, Thuy NTT, Gooley GJ, Ingram BA, Hao NV, Phuong NT, Silva SSD (2009) Current status of farming practices of striped catfish, Pangasianodon hypophthalmus in the Mekong Delta, Vietnam. J Aquac 296:227-236

Posthuma L, Suter GW, Traas TP (2002). Species sensitivity distributions in ecotoxicology. CRC Press LLC.

Raimondo S, Vivian DN, Barron MG (2009) Standardizing acute toxicity data for use in ecotoxicology models: influence of test type, life stage and concentration reporting. Ecotoxicology 18:918-928

Ricepedia (2016). The online authority on rice, http://ricepedia. org/vietnam/, accessed: 2016-02-05.

Roessink I, Merga BE, Zweers HJ, Van den Brink PJ (2013) The neonicotinoid imidacloprid shows high chronic toxicity to mayfly nymphs. Env Tox Chem 32(5):1096-1100

Sanh NV, Xuan V-T, Phong TA (1998) History and future of farming systems in the Mekong Delta. In: Xuan V-T, Matsui S (eds) Development of farming systems in the Mekong Delta of Vietnam JIRCAS, CTU \& CLRRI. Ho Chi Minh Publishing House, Ho Chi Minh, pp. $17-80$

Schreinemachers P, Afari-Sefa V, Heng CH, Dung PTM, Praneetvatakul S, Srinivasan R (2015) Safe and sustainable crop protection in Southeast Asia: status, challenges and policy options. Environ Sci Pol 54:357-366

Sebesvari Z, Le HTT, Toan PV, Arnold U, Renaud FG (2012) Agriculture and water quality in the Vietnamese Mekong Delta in: Renaud FG, Kuenzer C (eds). The Mekong Delta System: Interdisciplinary Analyses of a River Delta, Springer Environmental Science and Engineering. doi:10.1007/978-94-007-3962-8_13

Tam TN, Berg H, Hang TTN, Cong VN (2015a) Effects of chlorpyrifos ethyl on acetylcholinesterase activity in climbing perch cultured in rice fields in the Mekong Delta,Vietnam. Ecotoxicol Environ Saf $117: 34-40$

Tam TN, Berg H, Tuyen PTB, Cong NV (2015b). Effect of Chlorpyrifos ethyl on acetylcholinesterase activity in climbing perch (Anabas testudineus, Bloch, 1972). Archives of Environmental Contamination and Toxicology, Online First DOI 10.1007/s00244-015-0182-3.

Tam TN, Berg B, Cong VN (2016a) Evaluation of the joint toxicity of chlorpyrifos ethyl and fenobucarb on climbing perch (Anabas testudineus) from rice fields in the Mekong Delta, Vietnam. Environ Sci Pollut Res. doi:10.1007/s11356-016-6980-y

Tam TN, Berg H, Lauraeus, J. Cong VN, Tedengren M (2016b) Effects of sequential applications of Fenobucarb and Chlorpyrifos ethyl on acetylcholinesterase activity in climbing perch (Anabas testudineus) cultured in rice fields in the Mekong Delta, Vietnam. Bulletin of Environmental Contamination and Toxicology. DOI: 10.1007 /s00128-016-1796-5

Toan PV, Sebesvari Z, Bläsing M, Rosendahl I, Renaud FG (2013) Pesticide management and their residues in sediments and surface and drinking water in the Mekong Delta, Vietnam. Sci Total Environ 452-453:28-39

US EPA (2016) ECOTOX database. http://cfpub.epa.gov/ecotox/ . Accessed 20 Sept 2016

Van de Fliert E, Dung NT, Henriksen O, Tang Dalsgaard JP (2007) From collectives to collective decision-making and action: farmer field schools in Vietnam. J Agric Educ Ext 13(3):245-256. doi:10.1080/13892240701427706

Van den Brink PJ, Roelsma J, Van Nes EH, Scheffer M, Brock TCM (2002) PERPEST model, a case-based reasoning approach to predict ecological risks of pesticides. Env Tox Chem 21:2500-2506

Van den Brink PJ, Blake N, Brock TCM, Maltby L (2006) Predictive value of species sensitivity distributions for effects of herbicides in freshwater ecosystems. Hum Ecol Risk Assess 12:645-674

Van den Brink PJ, Van Smeden JM, Bekele RS, Dierick W, De Gelder DM, Noteboom M, Roessink I (2016) Acute and chronic toxicity of neonicotinoids to nymphs of a mayfly species and some notes on seasonal differences. Environ Toxicol Chem 35:128-133

Van Vlaardingen P, Traas TP, Aldenberg T (2003) Normal distribution based hazardous concentration and potentially affected fraction, ETX-2000. Rijksinstituut voor Volksgezondheid en Milieu, Bilthoven, the Netherlands

Van Wijngaarden RPA, Maltby L, Brock TCM (2015) Acute tier-1 and tier-2 effect assessment approaches in the EFSA aquatic guidance document: are they sufficiently protective for insecticides? Pest Manag Sci 71(8):1059-1067

WHO, World Health Organization (2010) The WHO recommended classification of pesticides by hazard and guidelines to classification: 2009. IPCS, International Program on Chemical Safety 